\title{
Green tea extract modulates lithium-induced thyroid follicular cell damage in rats
}

\author{
S.M. Zaki1, 2, G.H.A. Hussein³, G.M. Helal'4, S.F. Arsanyos², W.A. Abd Algaleel² \\ ${ }^{1}$ Department of Anatomy, Fakeeh College for Medical Sciences, Jeddah, Saudi Arabia \\ ${ }^{2}$ Department of Anatomy and Embryology, Faculty of Medicine, Cairo University, Egypt \\ ${ }^{3}$ Department of Anatomy and Embryology, Faculty of Medicine, Beni Suef University, Egypt \\ ${ }^{4}$ Department of Medical Biochemistry, Faculty of Medicine, Mansoura University, Egypt \\ [Received: 19 March 2021; Accepted: 6 May 2021; Early publication date: 17 May 2021]
}

Background: The aim of the current work was to clarify the modulation role of green tea extract (GTE) over structural and functional affection of the thyroid gland after long term use of lithium carbonate (LC). The suggested underlying mechanisms participating in thyroid affection were researched.

Materials and methods: Twenty-four Sprague-Dawley adult albino rats were included in the work. They were divided into three groups (control, LC, and concomitant LC + GTE). The work was sustained for 8 weeks. Biochemical assays were performed (thyroid hormone profile, interleukin 6 [II-6]). Histological, histochemical (Periodic Acid Schiff [PAS]) and immunohistochemical (caspase-3, tumour necrosis factor alpha [TNF- $\alpha$ ], proliferating cell nuclear antigen [PCNA]) evaluations were done. Oxidative/antioxidative markers (malondialdehyde [MDA]/gluthathione [GSH], superoxide dismutase [SOD]) and Western blot evaluation of the $B c / 2$ family were done. Results: Lithium carbonate induced hypothyroidism (decreased T3, T4/increased thyroid-stimulating hormone [TSH]). The follicles were distended, others were involuted. Some follicles were disorganised, others showed detached follicular cells. Apoptotic follicular cells were shown (BAX and caspase-3 increased, $B c / 2$ decreased, $B A X / B C / 2$ ratio increased). The collagen fibres' content and proinflammatory markers (TNF- $\alpha$ and IL-6) increased. The proliferative nuclear activity was supported by increased expression of PCNA. Oxidative stress was established (increased MDA/decreased GSH, SOD). With the use of GTE, the thyroid hormone levels increased, while the TSH level decreased. Apoptosis was improved as BAX decreased, $B C / 2$ increased, and BAX/BCl2 ratio was normal. The collagen fibres' content and proinflammatory markers (TNF- $\alpha$ and IL-6) decreased. The expression of PCNA and caspase-3 were comparable to the control group. The oxidative markers were improved (decreased MDA/increased GSH, SOD).

Conclusions: In conclusion, prolonged use of $L C$ results in hypothyroidism, which is accompanied by structural thyroid damage. LC induced thyroid damage through oxidative stress that prompted sterile inflammation and apoptosis. With the use of GTE, the thyroid gland regained its structure and function. The protecting role of GTE is through antioxidant, antifibrotic, anti-inflammatory, and antiproliferative effects. (Folia Morphol 2022; 81, 3: 594-605)

Key word: lithium carbonate, green tea extract, thyroid damage, oxidative stress, inflammation, apoptosis 


\section{INTRODUCTION}

Lithium and its salts such as lithium carbonate (LC) are commonly used for the treatment of numerous psychiatric illnesses [11]. It is used in the therapy of mood instability (bipolar disorder) and has a prospective role in the therapy of mania and depression [23]. It precludes mood swings in patients with manic-depressive disorder [7]. Although it is a unique drug, prolonged treatment with therapeutic levels may cause multisystem toxicity [25]. It can disturb the function of the heart, liver, kidney, testes, and gastrointestinal system. Additionally, it can induce diabetes insipidus, acneform eruptions, renal toxicity, and brain damage $[15,28,43,45]$.

The concentration level of lithium in the thyroid gland is 3-4 times that in plasma [5]. Lithium influences the function of the thyroid gland, either directly or indirectly via the hypothalamic-pituitary-thyroid axis [27]. It interferes with thyroid functions at the stage of hormonal secretion [13]. It competes for iodide transport, increases thyroidal radioiodine retention, and decreases deiodination from T4 to T3 [27]. It may cause hypothyroidism, goitre, or infrequently thyrotoxicosis [13]. Some researchers reported lithium-induced hypothyroidism was associated with oxidative stress [49]. Furthermore, others described the alteration of the thyroid gland at the cellular and subcellular levels [51].

Green tea (GT) is one of the common beverages in the globe. Its chief components are the polyphenol (catechins) [44]. GT catechins are epigallocatechin, epigallocatechin-3-gallate (EGCG), epicatechin, and epicatechin-3-gallate [12]. Moreover, GT contains caffeine, quercetin, chlorogenic acid, garlic acid, myricetin, and kaempferol [44]. GT polyphenols have protective roles against neurodegenerative diseases, cancer, heart disease, lung damages, and diabetes [21, 44].

The mechanism through which LC induces thyroid damage at the cellular level is not clearly understood and not enough studied. Furthermore, no works have investigated the protective role of green tea extract (GTE) over such damage. So, the present work intended to clarify the modulation role of GTE over structural and functional affection of thyroid gland after long term use of LC. The suggested underlying mechanisms participating in thyroid affection were investigated.

\section{MATERIALS AND METHODS}

\section{Animals}

Twenty-four Sprague-Dawley adult albino rats were included in the work. They were housed in a dark/light cycle (12/12 h), humidity (50-60\%) and temperature $\left(25 \pm 1^{\circ} \mathrm{C}\right)$. The study was completed in the Experimental Animal Centre, Faculty of Medicine, Cairo University, Egypt.

\section{Experimental design}

The rats were distributed into three groups (8 in each group): control, LC, and GTE (concomitant LC + GTE).

\section{Ethical approval}

All relevant international, national, and/or institutional guidelines for the care and use of animals were followed. The study was permitted by the Ethics Committee, Faculty of Medicine, Cairo University, Egypt.

\section{Test materials}

Lithium carbonate was obtained in the form of tablets (400 mg) (Nile Co. for Pharmaceuticals and Chemical Industries, Egypt). Tablets were liquefied in distilled water and given through an intragastric tube in a dose of $30 \mathrm{mg} / \mathrm{kg} /$ day for 8 weeks [10].

Green tea extract was obtained in the form of tablets (200 mg) (Techno-med Group Co., Egypt). Tablets were melted in distilled water and given orally in a dose of $150 \mathrm{mg} / \mathrm{kg} /$ day for 8 weeks [19].

\section{General health profile}

Food and water intake, motility, and health condition were recorded daily. Bodyweight (BW) was documented at the start and end of the study.

\section{Biochemical assay}

The serum levels of total T3 (TT3), free T3 (FT3), total T4 (TT4), free T4 (FT4) and thyroid-stimulating hormone (TSH) were determined by radioimmunoassay (xh6080, Xi'an). The inflammatory marker interleukin 6 (IL-6) was assessed by the commercially ELISA kits according to manufacturer's instructions.

\section{Tissue sampling}

Thyroid was dissected and fixed in $10 \%$ formalin saline. The tissue was sectioned every $10^{\text {th }}$ section ( $5 \mu \mathrm{m}$ thick). The thyroid tissue extract was prepared according to Gordon et al. [14].

\section{Light microscopic study}

Haematoxylin and eosin (H\&E) and Masson's trichrome stained sections were prepared according to Suvarna et al. [45]. 


\section{Histochemical evaluation (PAS stain)}

Histochemical evaluation (Periodic Acid-Schiff [PAS]-stained) sections were prepared according to Suvarna et al. [45].

\section{Immunohistochemistry [41]}

Paraffin sections were prepared. Then, suitable quantity of serum was added to the sections for $30 \mathrm{~min}$.

Caspase-3. The sections were incubated with anti-active caspase-3 antibody (cataloque number: ab13847, Abcam, Cambridge, UK), then followed with biotinylated secondary antibody (LSAB kit, Dako Carpentaria, CA, USA). After that, they were incubated with streptavidin HRP (LSAB kit, Dako, Carpentaria, CA, USA), and then with 3'-diaminobenzidine (0.05\% DAB).

Tumour necrosis factor alpha (TNF- $\alpha$ ). The sections were incubated with the primary monoclonal anti-TNF- $\alpha$ antibody (52B83) using dilutions 1:5000 for $36 \mathrm{~h}$ at $4^{\circ} \mathrm{C}$. Then, they were incubated with biotinylated secondary antibodies for $5 \mathrm{~h}$ and then with Avidin-Biotin-Peroxidase Complex $(A B C)$. Finally, the immune reaction was visualised with $0.05 \%$ DAB.

PCNA immunostaining. Proliferating cell nuclear antigen (PCNA) is a helper protein of DNA polymerase enzymes and is used as a typical marker for proliferating cells [38]. The immunostaining essential pretreatment was done by boiling for $10 \mathrm{~min}$ in 10 $\mathrm{mmol} / \mathrm{L}$ citrate buffer (catalogue number AP 9003) (pH 6) for antigen retrieval. Then, the sections were incubated with the primary antibody (a rabbit polyclonal antibody) (catalogue number ab15497, Abcam, Cambridge, UK). Immunostaining was finalised by using the Ultra-vision detection system (catalogue number TP-015-HD). The small intestine was used as a positive-control section. The positive reaction appeared as brown nuclear colouration [38].

\section{Oxidative/antioxidative markers}

Thyroid lipid peroxidation. Malondialdehyde (MDA) was measured using the method of Buege [8]. Briefly, $100 \mu \mathrm{L}$ serum was diluted with distilled water to $500 \mu \mathrm{L}$. One $\mathrm{mL}$ of TBA-HCl reagent was added to the diluted sample. The reaction mixture was centrifuged, and the supernatant was taken. The optical density was measured spectrophotometrically at 532 $\mathrm{nm}$. The concentration of MDA in the sample was got by plotting the obtained absorbance against the standard graph.
Thyroid superoxide dismutase (SOD). SOD was measured according to the modified Misra and Fridovich's method [35]. Ten $\mu \mathrm{L}$ of bovine catalase and $1965 \mu \mathrm{L}$ of $\mathrm{Na} 2 \mathrm{CO} 3$ buffer were added to $5 \mu \mathrm{L}$ of $10 \%$ thyroid homogenate. Then, the mixture was added to $20 \mu \mathrm{L}$ of $30 \mathrm{mM}$ epinephrine in $0.05 \%$ ethanoic acid. The activity of SOD was determined at $37^{\circ} \mathrm{C}$ at $480 \mathrm{~nm}$ in a spectrophotometer (Model BL 158, ELICO) at 0 minutes and after 3 minutes. The activity of SOD was expressed as the quantity of the enzyme that impedes the oxidation of epinephrine by $50 \%$ $=1 \mathrm{U} / \mu \mathrm{g} / \mathrm{mg}$ tissue protein.

Thyroid glutathione (GSH). The measurement of GSH was constructed on the reduction of DTNB with GSH to produce a yellow compound. The reduced chromogen was measured at $405 \mathrm{~nm}$. The concentration of the GSH was calculated using the standard curve and expressed/mg of tissue protein [48].

\section{Morphometric analysis}

The content of collagen fibres and the optical density of PAS in colloids and follicular basement membranes were assessed. Adding, the immune expression of TNF- $\alpha$, caspase- 3 positive follicular cell nuclei (\%), and the PCNA positive follicular cell nuclei (\%) were evaluated using the Leica LAS V3.8 image analyser computer system (Switzerland).

\section{Western blot}

The homogenised thyroid tissue was added to the ReadyPrep ${ }^{\mathrm{TM}}$ protein extraction kit (Bio-Rad Inc., catalogue number $163-2086)$. Twenty $\mu \mathrm{g}$ protein concentration was loaded with an equal volume of $2 \times$ Laemmle sample buffer. Primary antibodies of $\mathrm{BCl} 2$ and $\mathrm{BCl}-2$-associated $X$ protein (BAX) (Santa Cruz Biotechnology, Inc., catalogue numbers: sc-7382 and sc-7480) were diluted in TBST and incubated overnight against the blotted target protein followed by incubation with the HRP-conjugated secondary antibody (Goat anti-rabbit IgGHRP-1 mg Goat Novus Biologicals) solution for $1 \mathrm{~h}$ at RT. The chemiluminescent substrate (Clarity ${ }^{\mathrm{TM}}$ Western ECL substrate Bio-Rad, cataloque number 170-5060) was applied to the blot.

\section{Statistical analysis}

Statistical evaluation was performed using SPSS version 21 (IBM Corporation, Somers, NY, USA) statistical software. Data were stated as means \pm standard 
Table 1. Body weight (BW) in the different groups at the end of study

\begin{tabular}{lccc}
\hline Group & $\begin{array}{c}\text { BW }[\mathrm{g}] \\
\text { Mean } \pm \text { SD }\end{array}$ & Versus group & P value \\
\hline Control & $200 \pm 22.5$ & & \\
LC-treated & $245.5 \pm 30.8$ & Control & $0.01^{*}$ \\
& & GET-treated & $0.03^{*}$ \\
GTE-treated & $215.6 \pm 18.4$ & Control & 0.1 \\
& & LC-treated & $0.03^{*}$ \\
\hline
\end{tabular}

*P-value significant; the BW at the beginning of the study was $160.5 \pm 17.1 \mathrm{~g}$; BW bodyweight; GTE — green tea extract; LC — lithium carbonate; SD — standard deviation

deviation. Statistical analysis was done by mean of ANOVA tracked by Bonferroni pairwise comparisons.

\section{RESULTS}

\section{The general health data}

The water and food consumption and health condition were relatively exceptional in all groups. At the beginning of the study, the BW was $160.5 \pm$ $\pm 17.1 \mathrm{~g}$. By the end of the experiment, the BW of the LC group increased by $21 \%$ compared to the control group. Simultaneous administration of GTE along with LC ameliorates the weight gain (12\% decrease) as compared to the LC group. BW of the control and GTE groups were similar (Table 1).

\section{Hormonal results}

The LC group exhibited a significant decrease in TT3, TT4 $(29,32 \%)$ and FT3, FT4 $(53,50 \%)$ compared to the control group. Adding, the TSH level in this group increased by $161 \%$ compared to the control group (Table 2).

With the use of GTE, the serum level of TT3, TT4, FT3, FT4 increased by $16 \%, 23 \%, 28 \%, 22 \%$ compared to the control group. Moreover, the TSH level in this group decreased (45\%) compared to the LC group; however, its' level was still higher (41\%) than that of the control group (Table 2).

\section{Histopathology of the thyroid gland}

The follicles of the control group were lined by cubical cells and contained acidophilic homogenous colloid (Fig. 1A).

The follicles in the LC group showed variable activities; some follicles were distended, while others were involuted. The distended follicles were lined by flat cells. Moreover, some follicles were disorganised with wide interfollicular spaces. Furthermore, some follicles had detached follicular cells inside the colloid. The follicular cells were mostly vacuolated. Finally, congested-capillary vessels were detected (Fig. 1B-E). With the use of GTE, the thyroid architecture looked almost normal (Fig. 1F).

\section{Content of collagen fibres}

The fibres' content increased 2-fold in the LC group compared to the control group. Much advance was perceived in the GTE group as its fibres' content was 1-fold compared to the control group. The fibres' content in the GTE group was $37 \%$ lower compared to the LC group (Fig. 2, Table 3).

\section{Histochemistry of the thyroid gland}

In the control group, the follicular cells displayed strong PAS reactions in colloids and basal laminae (Fig. 3A, Table 3). The basal laminae of the follicular cells in the LC group revealed weak PAS reactions. The colloids revealed moderate PAS reactions, while the reactions were absent in the vacuoles of colloids. The disrupted basement membranes displayed discontinuous PAS reaction. The reaction was $64 \%$ lower than in the LC group (Fig. 3B, C, Table 3). After the

Table 2. Thyroid function tests at the end of the study

\begin{tabular}{llccccc}
\hline Group & & TSH & TT3 [ng/mL] & FT3 [pmol/L] & TT4 $[\mu \mathrm{g} / \mathrm{dL}]$ & FT4 [pmol/L] \\
\hline Control & Mean \pm SD & $3.6 \pm 0.3$ & $6.2 \pm 0.5$ & $16.7 \pm 0.8$ & $21.2 \pm 1.0$ & $32.9 \pm 3.2$ \\
LC-treated & Mean \pm SD & $9.4 \pm 1.3$ & $4.4 \pm 0.2$ & $7.7 \pm 1.2$ & $14.4 \pm 1.7$ & $16.3 \pm 3.0$ \\
& Versus control & $<0.001^{*}$ & $<0.001^{*}$ & $<0.001^{*}$ & $<0.001^{*}$ & $<0.001^{*}$ \\
& Versus GTE-treated & $<0.001^{*}$ & $0.01^{*}$ & $<0.001^{*}$ & 0.055 & $0.002^{*}$ \\
GTE-treated & Mean \pm SD & $\mathbf{5 . 1} \pm \mathbf{0 . 3}$ & $\mathbf{5 . 2} \pm 0.4$ & $12.0 \pm 0.8$ & $17.2 \pm 2.1$ & $25.4 \pm 3.0$ \\
& Versus control & $<0.001^{*}$ & $0.002^{*}$ & $<0.001^{*}$ & $0.007^{*}$ & $0.007^{*}$ \\
& Versus LC-treated & $<0.001^{*}$ & $0.01^{*}$ & $<0.001^{*}$ & 0.055 & $0.002^{*}$ \\
\hline
\end{tabular}

${ }^{*} \mathrm{p}$-value significant; GTE — green tea extract; LC — lithium carbonate; SD — standard deviation; FT3 — free T3; FT4 — free T4; TT3 — total T3; TT4 — total T4; TSH — thyroid-stimulating hormone 

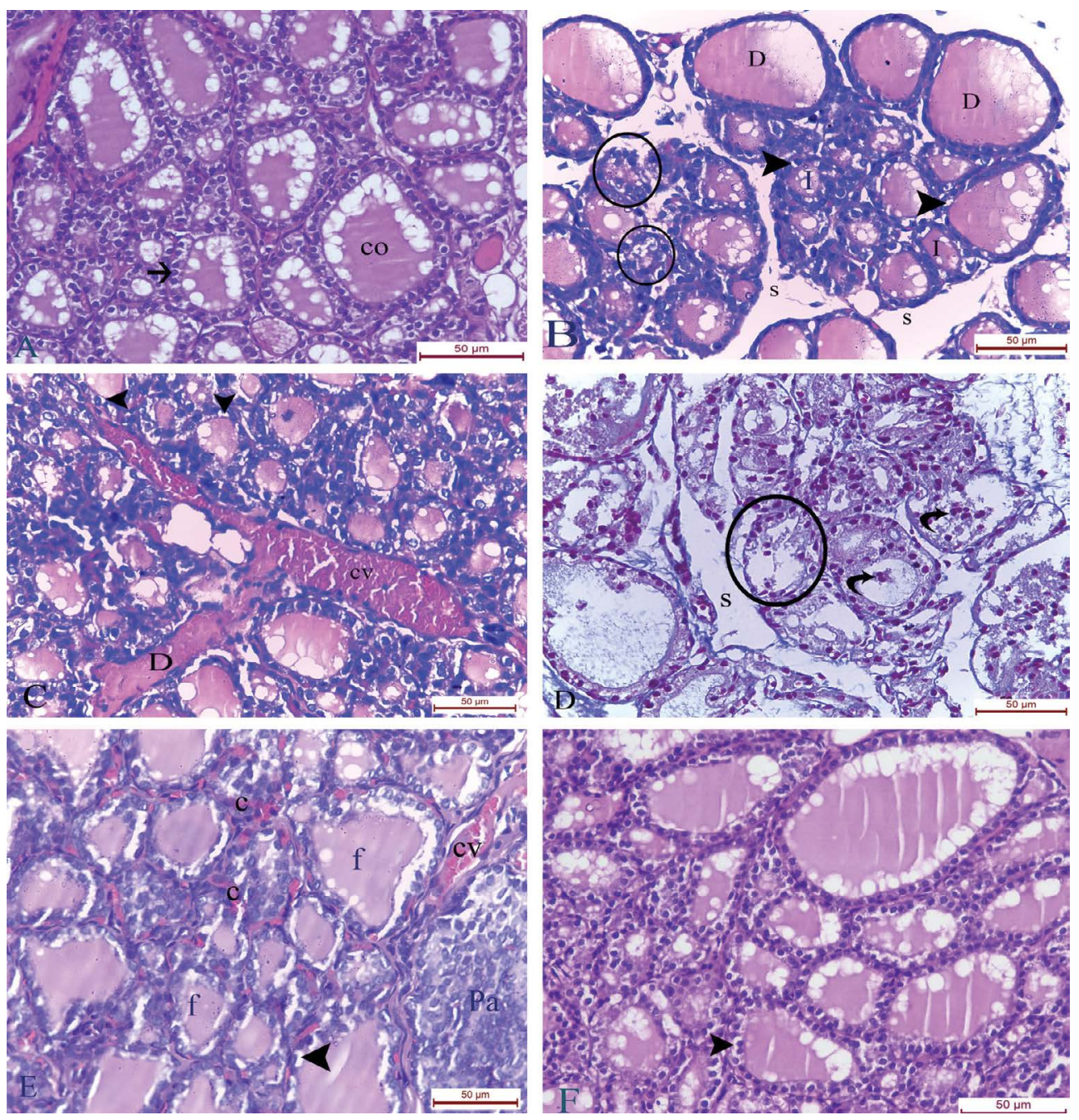

Figure 1. A. Normal follicles of the control rats. Note simple cuboidal follicular cells (arrows) surrounding homogenous acidophilic colloid (co); B-E. Thyroid follicles of lithium carbonate group; B. Some follicles are distended (D), others are involuted (I). Note damaged and disorganised follicles (encircled) with a large interfollicular space (S). Note follicular cells with vacuolated cytoplasm (arrowheads); C. Markedly distended thyroid follicle (D). Note congested-capillary vessel (CV) and follicular cells with vacuolated cytoplasm (arrowheads); D. Loss of normal thyroid architecture. Most of the follicles have shredded epithelial lining (curved arrows) and have no colloid. Note disorganized follicles (encircled) with a large interfollicular space (S); E. Thyroid follicles (F) with vacuolated cells (arrowheads). Note congested-capillary vessel (CV), interfollicular spaces with extravasated blood (c). Notice part of the parathyroid gland (Pa); F. Nearly normal thyroid architecture of the green tea extract rats. Note follicular cells with vacuolated cytoplasm (arrowheads). Haematoxylin and eosin $\times 400$.

concomitant treatment with GTE, the PAS reaction was strong in colloids and basement membranes. The reaction was comparable to the control group and was $>1$-fold higher than that of the LC group (Fig. 3D, Table 3).

\section{Immunohistochemistry of the thyroid gland}

The control group displayed positive PCNA follicular cell nuclei (Fig. 4A). The LC group displayed an increased number of positive PCNA follicular cell nuclei (6.5-fold higher compared to the control group) (Fig. 4B, C, Table 3). The use of GTE was related to a 2 -fold increase in the number of positive PCNA follicular cell nuclei com- pared to the LC group. The expressions in the control and GTE groups were identical (Fig. 4D, Table 3).

The control group displayed weak caspase- 3 expression of the follicular cell nuclei (Fig. 5A). The LC group showed strong expression in the follicular cell nuclei (2-fold higher compared to the control group) (Fig. 5B, C, Table 3). The administration of GTE was related to a 1-fold increase in the expression in the cell nuclei compared to the LC group. The expressions in the control and GTE groups were similar (Fig. 5D, Table 3).

The control group showed weak expression of TNF- $\alpha$ of the follicular cells (Fig. 6A). The expression 


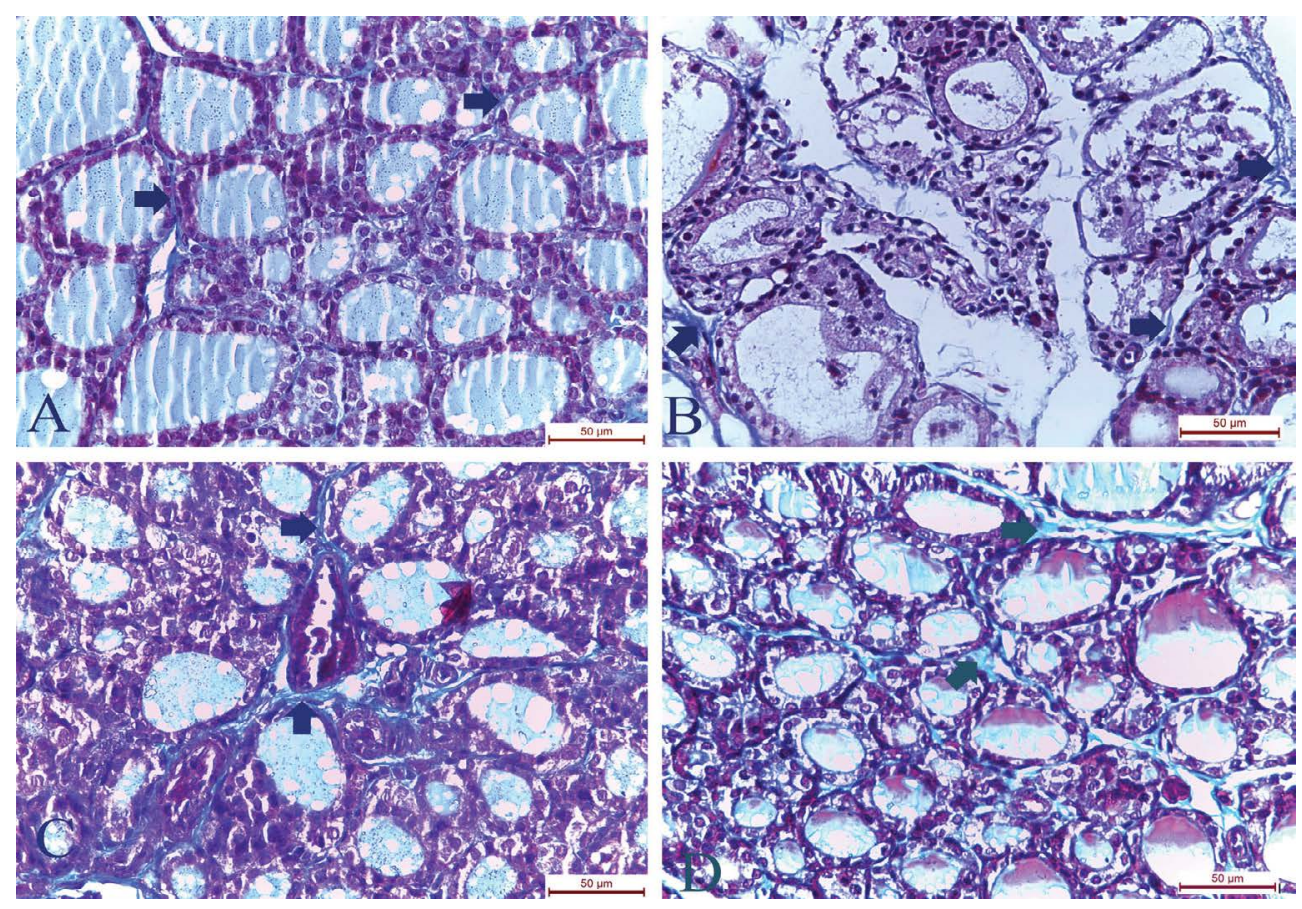

Figure 2. A. The collagen fibres (arrows) between thyroid follicles in the control; B, C. Increased collagen fibres (arrows) between thyroid follicles in the lithium carbonate rats; C. Negligible collagen fibres (arrows) between thyroid follicles in the green tea extract rats. Masson's trichrome $\times 400$.

Table 3. Collagen fibres, Periodic Acid Schiff (PAS) reaction, apoptotic and proliferative markers

\begin{tabular}{|c|c|c|c|c|c|c|c|c|}
\hline Group & & $\begin{array}{l}\text { Content of } \\
\text { collagen } \\
\text { fibres }\end{array}$ & $\begin{array}{l}\text { Optical den- } \\
\text { sity of PAS } \\
\text { reaction }\end{array}$ & $\begin{array}{c}\text { Caspase-3 } \\
\text { positive } \\
\text { cells ( } \% \text { of } \\
\text { total cells) }\end{array}$ & $\begin{array}{c}\text { PCNA } \\
\text { positive } \\
\text { cells ( } \% \text { of } \\
\text { total cells) }\end{array}$ & BAX & Bcl2 & $\begin{array}{c}\mathrm{BAX} / \mathrm{Bcl} 2 \\
\text { ratio }\end{array}$ \\
\hline Control & Mean \pm SD & $18.2 \pm 5.9$ & $0.31 \pm 0.06$ & $4.0 \pm 1.6$ & $12.8 \pm 1.9$ & $0.83 \pm 0.05$ & $2.73 \pm 0.16$ & $0.27 \pm 0.05$ \\
\hline \multirow[t]{3}{*}{ LC-treated } & Mean \pm SD & $55.2 \pm 8.2$ & $0.11 \pm 10.06$ & $30.0 \pm 7.9$ & $38.8 \pm 6.3$ & $2.44 \pm 0.16$ & $1.11 \pm 0.05$ & $2.42 \pm 0.39$ \\
\hline & Versus control & $<0.001^{*}$ & $<0.001^{*}$ & $<0.001^{*}$ & $<0.001^{*}$ & $<0.001^{*}$ & $<0.001^{*}$ & $<0.001^{*}$ \\
\hline & Versus GTE-treated & $0.003^{*}$ & $0.005^{*}$ & $<0.001^{*}$ & $<0.001^{*}$ & $<0.001^{*}$ & $<0.001^{*}$ & $<0.001^{*}$ \\
\hline \multirow[t]{3}{*}{ GTE-treated } & Mean \pm SD & $37.4 \pm 5.0$ & $0.24 \pm 0.04$ & $12.6 \pm 2.8$ & $23.2 \pm 3.3$ & $1.31 \pm 0.07$ & $2.32 \pm 0.706$ & $0.54 \pm 0.03$ \\
\hline & Versus control & $0.002^{*}$ & 0.144 & 0.052 & $0.007^{*}$ & $<0.001^{*}$ & $<0.001^{*}$ & 0.259 \\
\hline & Versus LC-treated & $0.003^{*}$ & $0.005^{*}$ & $<0.001^{*}$ & $<0.001 *$ & $<0.001 *$ & $<0.001^{*}$ & $<0.001^{*}$ \\
\hline
\end{tabular}

*p-value significant; BAX — Bcl-2-associated X protein; GTE — green tea extract; LC — lithium carbonate; PCNA — proliferating cell nuclear antigen; SD — standard deviation

in the LC group was strong (2-fold higher compared to the control group) (Fig 6B, C, Table 4). The use of GTE was related to a 1 -fold increase in the expression in the follicular cell compared to the LC group. The expressions in the control and GTE groups were similar (Fig. 6D, Table 4).

\section{Western blot evaluation of BAX and Bcl2 (Fig. 7, Table 3)}

The expression of BAX in the LC group increased by $190 \%$ (about 2 -fold) compared to the control group. The expression in the GTE group was $46 \%$ lower compared to the LC group, but still higher (57\%) compared to the control group.

The expression of $\mathrm{BC} 22$ in the $\mathrm{LC}$ group decreased by $59 \%$ compared to the control group. The expression in the GTE group was 1-fold higher compared to the LC group, but $15 \%$ lower compared to control group.

The $\mathrm{BAX} / \mathrm{Bcl} 2$ ratio was 8-fold higher compared to the control group. The ratios of the control and GTE groups were comparable. 

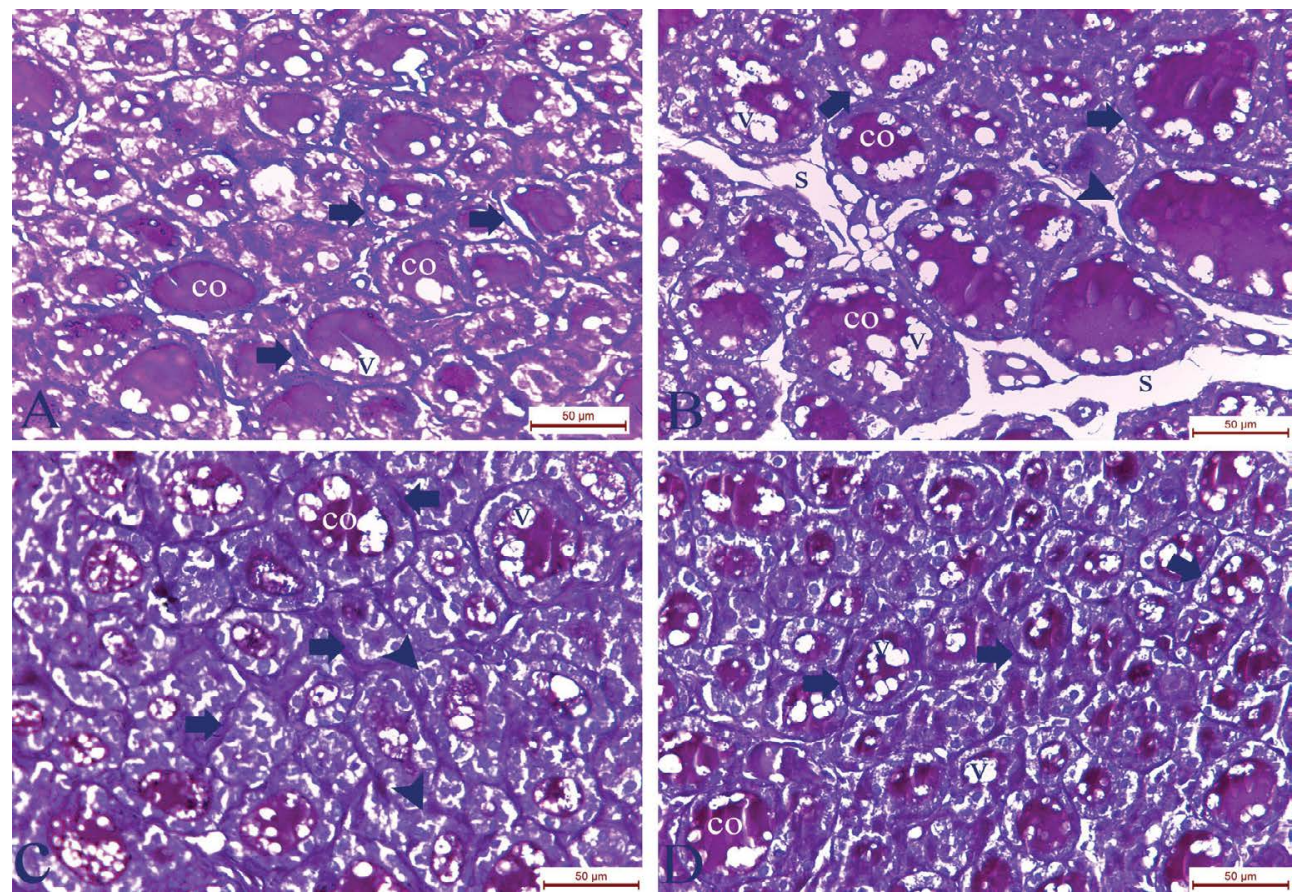

Figure 3. A. Strong Periodic Acid Schiff (PAS)-positive reaction in the colloid (co) and basement membranes (arrows) of the follicles with a negative reaction in the peripheral vacuoles of colloids $(v)$ in the control group; B, C. Weak PAS reaction in the basement membranes (arrows) of the follicles in the lithium carbonate group. The PAS reaction was moderate in colloids (co), while it was absent in peripheral vacuoles of colloids (v). Note discontinuous PAS-positive reaction in the disrupted basement membranes (arrowheads); D. Strong PAS-positive reaction in colloids (co) and basement membranes (arrows) of the follicles with a negative reaction in the minute peripheral vacuoles of colloids $(v)$ in the green tea extract group. PAS $\times 400$.
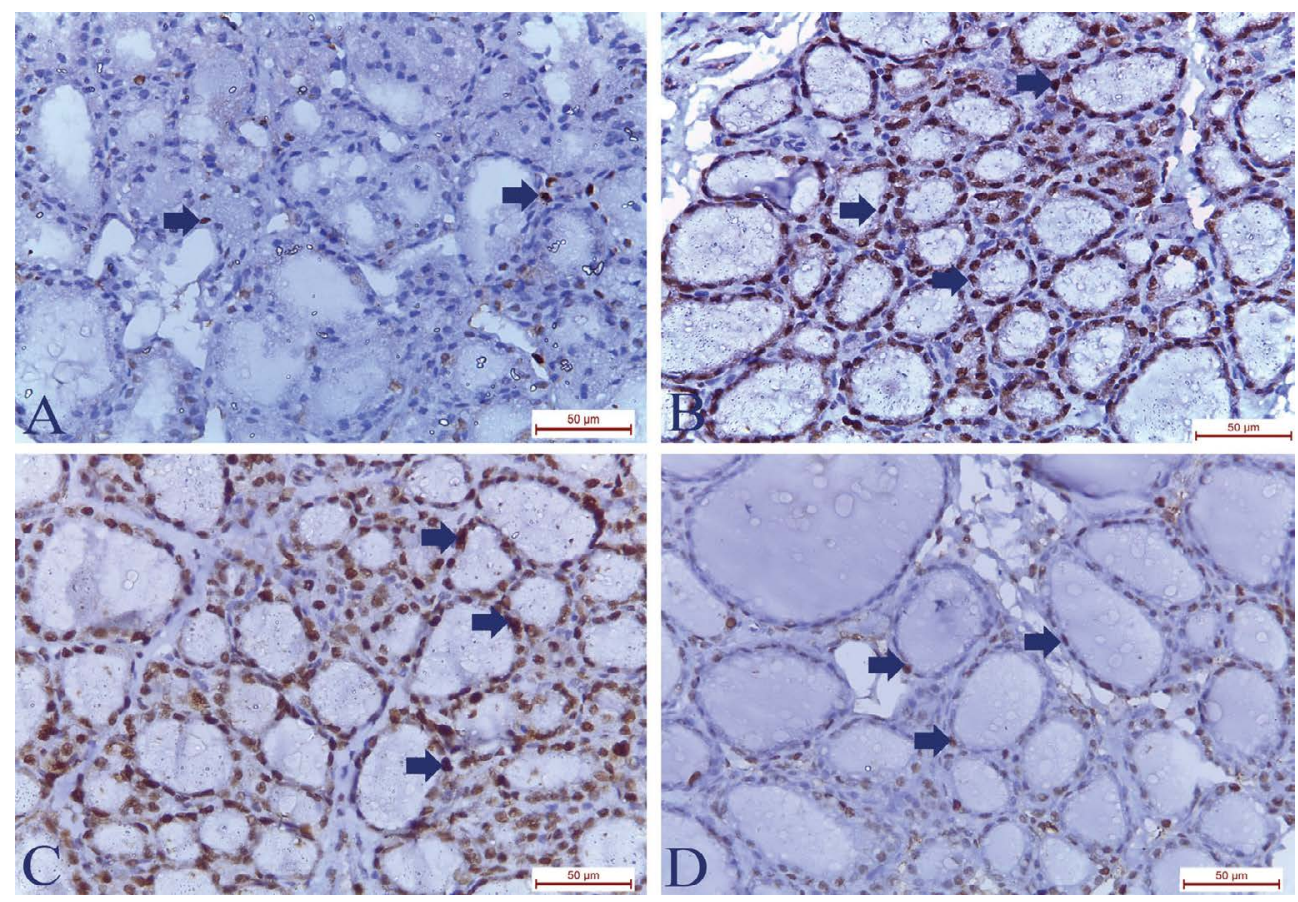

Figure 4. A. The number of proliferating cell nuclear antigen (PCNA) positive cells (arrows) in the control rats; B, C. Apparent increase in the number of PCNA positive cells (arrows) in the lithium carbonate rats; D. Slight increase in the number of PCNA positive cells (arrows) in the green tea extract rats. PCNA $\times 400$. 

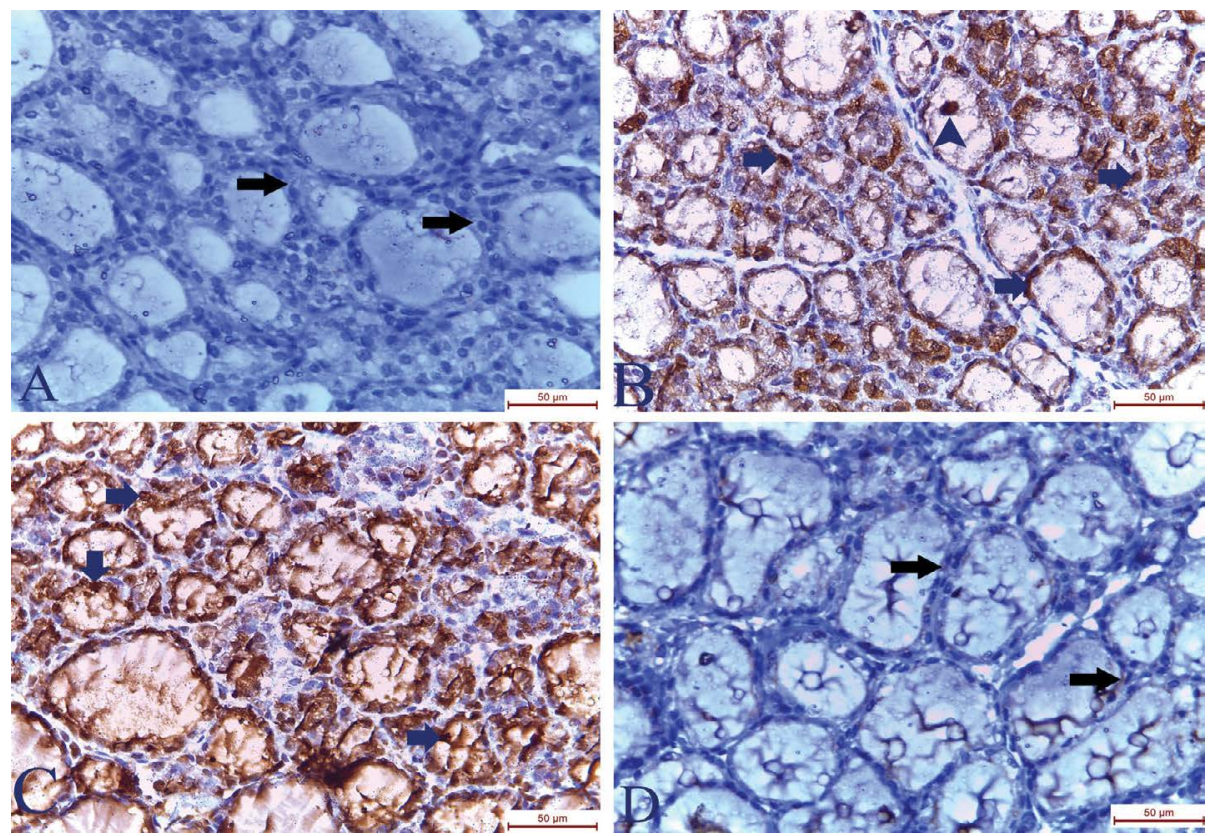

Figure 5. A. Control group exhibited weak caspase-3 expression in the follicular cell nuclei (arrows); B, C. The lithium carbonate group showed strong expression in the follicular cell nuclei (arrows); D. Slight expression in the follicular cell nuclei (arrows) in the green tea extract group. Caspase- $3 \times 400$.
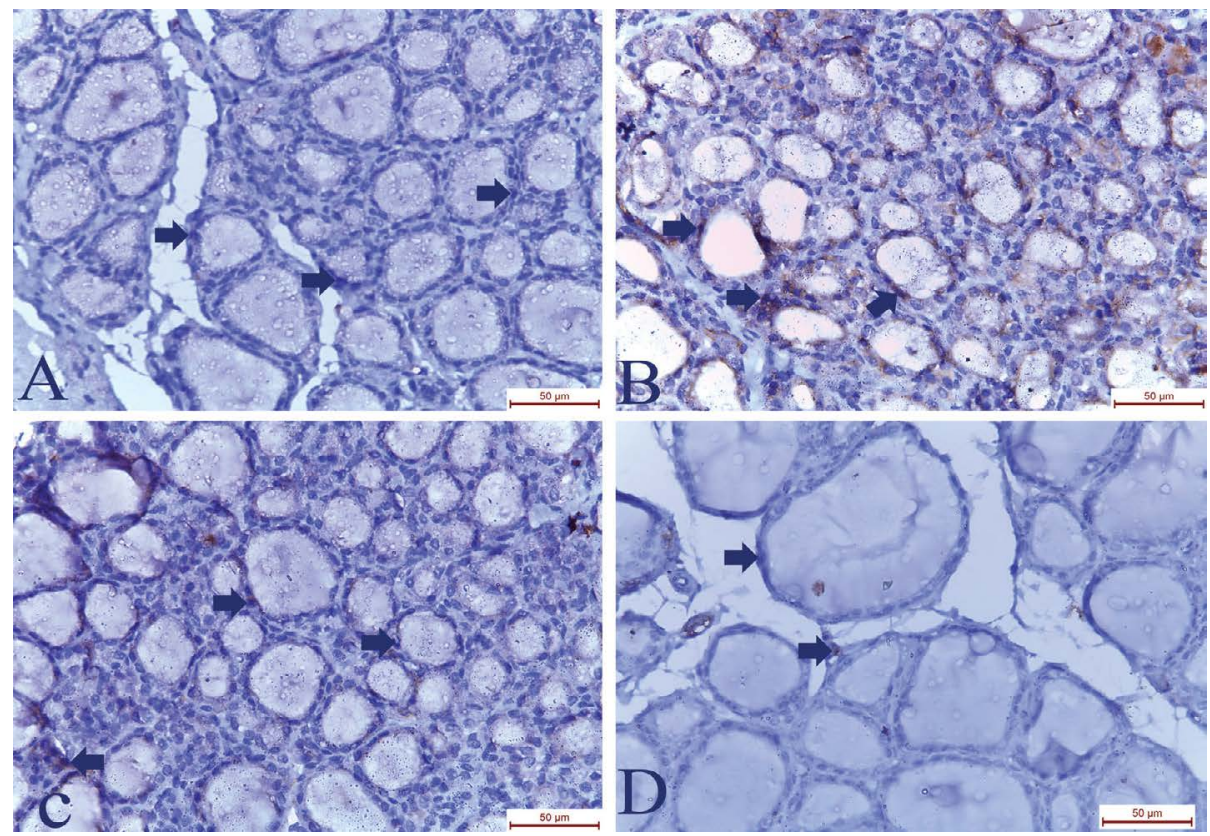

Figure 6. A. Control group displayed weak expression of tumour necrosis factor alpha (TNF- $\alpha$ ) in the follicular cell nuclei (arrows); B, C. The lithium carbonate group showed increased expression of TNF- $\alpha$ in the follicular cell nuclei (arrows); D. Slight increase in the expression of TNF- $\alpha$ in the follicular cell nuclei (arrows) in the green tea extract group. TNF- $\alpha \times 400$.

\section{Proinflammatory and oxidative markers assessment (Table 4)}

Interleukin 6 of the LC group was 5-fold higher compared to the control group. With the use of GTE, IL-6 became 2.5-fold higher compared to the control group.
Malondialdehyde of the LC group was $171 \%$ higher compared to the control group. With the use of GTE, MDA became $49 \%$ lower compared to the LC group; however, it was $47 \%$ higher compared to the control group. 
Table 4. Inflammatory and oxidative/antioxidative markers

\begin{tabular}{llccccc}
\hline Group & & $\begin{array}{c}\text { MDA [nmol/mg } \\
\text { tissue protein] }\end{array}$ & $\begin{array}{c}\text { GSH }[\mu \mathrm{g} / \mathrm{mg} \\
\text { tissue protein] }\end{array}$ & $\begin{array}{c}\text { SOD [nmol/mg } \\
\text { tissue protein] }\end{array}$ & $\begin{array}{c}\text { IL-6 [pg/mg } \\
\text { tissue protein] }\end{array}$ & $\begin{array}{c}\text { TNF-alpha [pg/mg } \\
\text { tissue protein] }\end{array}$ \\
\hline Control & Mean \pm SD & $1.53 \pm 0.16$ & $1.89 \pm 0.05$ & $7.1 \pm 0.46$ & $82.0 \pm 7.81$ & $64.6 \pm 10.04$ \\
LC-treated & Mean \pm SD & $4.16 \pm 0.41$ & $0.7 \pm 0.14$ & $2.98 \pm 0.4$ & $374.0 \pm 24.65$ & $388.0 \pm 16.84$ \\
& Versus control & $<0.001^{*}$ & $<0.001^{*}$ & $<0.001^{*}$ & $<0.001^{*}$ & $<0.001^{*}$ \\
& Versus GTE-treated & $<0.001^{*}$ & $<0.001^{*}$ & $<0.001^{*}$ & $<0.001^{*}$ & $<0.001^{*}$ \\
GTE-treated & Mean \pm SD & $2.25 \pm 0.09$ & $1.55 \pm 0.12$ & $5.9 \pm 0.3$ & $158.8 \pm 14.7$ & $243.00 \pm 30.02$ \\
& Versus control & $0.003^{*}$ & $0.01^{*}$ & $0.01^{*}$ & $<0.001^{*}$ & $<0.001^{*}$ \\
& Versus LC-treated & $<0.001^{*}$ & $<0.001^{*}$ & $<0.001^{*}$ & $<0.001^{*}$ & $<0.001^{*}$ \\
\hline
\end{tabular}

*p-value significant; GSH — gluthathione; GTE — green tea extract; IL-6 — interleukin 6; LC — lithium carbonate; MDA — malondialdehyde; SD — standard deviation; SOD — superoxide dismutase; TNF-alpha — tumour necrosis factor alpha

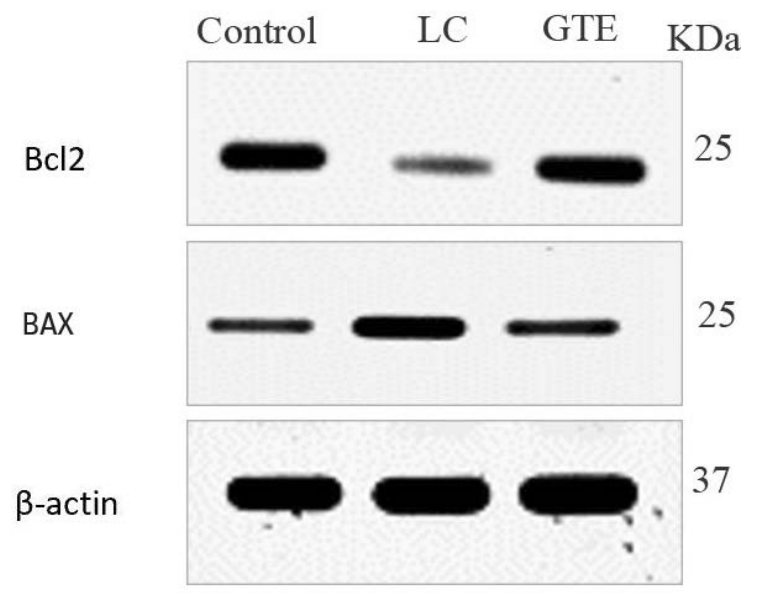

Figure 7. Western blot assay of $\mathrm{Bcl}$-2-associated $\mathrm{X}$ protein (BAX) and $B c \mid 2$. BAX was higher in the lithium carbonate (LC) group compared to the control. Bcl2 was lower in the green tea extract (GTE) group compared to the control. Beta-actin was used as a control.

Glutathione and SOD of the LC group decreased by $62,42 \%$ compared to the control. With the use of GTE, the antioxidant markers increased by 121 (97\%) compared to the LC group; however, both markers were $17,16 \%$ higher than in the control group.

\section{DISCUSSION}

Under our experimental condition, hypothyroidism induced by lithium was confirmed by a decrease in the level of thyroid hormones (TT3, TT4, FT3, FT4). LC influences its effects over the thyroid hormones either directly or indirectly via the hypothalamic-pituitary-thyroid axis [27].

Moreover, an increase in serum level of TSH occurs mostly secondary to the decreased thyroid hormone secretion. TSH is a thyrotropin hormone that is secreted from the pituitary gland and stimuluses the formation of T3 and T4 [17]. It is the key indicator of thyroid dysfunction [3]. The resultant hypersecretion of TSH specifies the commencement of hypothyroidism as described formerly in patients treated with LC [24]. The diagnostic characteristic of TSH emerges from the inverse linear relations between the serum TSH and FT4 level as tiny changes in T4 levels induces enormous changes in serum TSH $[2,3]$.

By the end of the work, the BW of the LC rats increased by $21 \%$ compared to the control group. The weight gain is typically related to low basal metabolic rates consequence to the hypothyroidism induced by LC [31].

The prolonged take of LC is associated with thyroid damage. The colloids are extensively vacuolated and depleted. The follicles either distended or involuted. Moreover, some follicles are disorganised with wide interfollicular spaces and detached follicular cells. Additional, the follicular cells show vacuolations.

The observed thyroid damage in the LC group is mostly multifactorial. Oxidative stress is one of the pathogenic mechanisms through which LC can induce thyroid damage at the cellular level. Many researchers proved the oxidative stress role of LC over many organs such as heart, kidney, and testis [34, 39]. Oxidative stress is a shift in the balance between oxidants and antioxidants in favour of oxidants [6]. With the prolonged use of LC, the oxidant marker (MDA) became high (171\%), while the antioxidant markers (GSH and SOD) became low (62\%, 42\%).

The resulting oxidative stress of LC creates oxygen free radical (ROS) that reacts with numerous biomolecules in the cell, leading eventually to oxidative damage [32]. ROS is scavenged by several cellular defence mechanisms involving non-enzymatic (GSH) and enzymatic (SOD) scavenger mechanisms. SOD catalyses the dismutation of $\mathrm{O}_{2}{ }^{-}$to $\mathrm{H}_{2} \mathrm{O}_{2}$ and $\mathrm{O}_{2}$ [22], while GSH offers protection against free radicals, per- 
oxides, and toxic compounds [33]. Prolonged use of LC decreased the activities of the free radical scavenging enzymes SOD and GSH. This results in augmented production of the $\mathrm{O}_{2}^{-}$and $\mathrm{H}_{2} \mathrm{O}_{2}$, which in turn leads to the production of $\mathrm{OH}^{-}$[18]. The generation of $\mathrm{OH}^{-}$ takes part in the observed thyroid toxic damage [18].

Higher lipid peroxidation (higher MDA), noticed in the LC group, led to distraction of the follicular basement membranes' integrity, and the cytoplasmic enzyme's leakage [9]. Many researchers believed that MDA's level is sufficient proof of oxidative stress [26]. So finally, the increased MDA content indicates severe oxidative stress and increased lipid peroxidation.

Sterile inflammation (inflammation in the absence of infection) is the second pathogenic mechanisms through which LC induced thyroid damage at the cellular level. Inflammation was evident by the increase in the pro-inflammatory cytokines (a 2-fold elevation in TNF- $\alpha$ and 5 -fold increase in IL-6). TNF- $\alpha$ is accountable for the pathogenesis of increases in ROS and oxidative stress [26]. It controls the growth, proliferation, differentiation, and viability of activated leukocytes [36]. Furthermore, TNF- $\alpha$ elicits the cellular release of cytokines, chemokines, or inflammatory mediators [36]. So, extreme TNF- $\alpha$ secretion results in thyroid injury indirectly through inducing oxidative stress, and directly through inducing apoptosis. The resultant fibrosis was consequent to oxidative stress and inflammation.

Congestion in the vasculature of the thyroid gland was a constant feature in the LC group. It is caused as a result of the increased demand for blood to feed the follicular cells or as a result of the increased thyroid gland's size [10]. Furthermore, congestion can be part of the previously stated inflammatory process that accompanies LC toxicity. Moreover, prolonged elevation of TSH induces neovascularisation and increases the stromal vascularity as TSH acts as a growth factor for the thyroid tissue [20].

Apoptosis is also a main pathogenic mechanism through which LC induced thyroid damage at the cellular level. Apoptosis is induced by higher levels of MDA and TNF- $\alpha[6,26]$. Apoptosis enhances the release of cytokines and ROS, which lastly damages thyroid gland [26].

The framework of the apoptotic signal pathway finally converges into a common mechanism driven by caspases [47]. Caspase-3 is the principal destroyer of apoptosis, thus sponsoring cell survival [30]. Caspase-3 of the LC group was 2-fold higher com- pared to the control. The caspase mechanism is negatively regulated by $\mathrm{BCl} 2$ family unit [1]. This family is classified into a family containing $\mathrm{BCl} 2$, a second family containing BAX, and a third family including Bik and Bid [50]. The Bcl2 exerts anti-apoptotic effect by impeding a step that leads to the activation of caspases, while BAX exerts proapoptotic activity [50]. With the use of $L C$, the expression of BAX increased 2-fold, while the expression of $\mathrm{BCl} 2$ decreased by $59 \%$. The $\mathrm{BAX} / \mathrm{BCl} 2$ ratio increased 8-fold. This ratio describes the accountability of the cell for apoptosis [50].

With prolonged exposure to $L C$, some follicular cells may pass into irreparable damage and undergo terminal growth arrest or apoptosis. However, other follicular cells may acquire an intrinsic mechanism of death resistance and finally lead to hyperplasia instead of apoptosis. Such hyperplasia was furtherly confirmed morphometrically by a significant increase in the number of PCNA positive follicular cell nuclei (6.5-fold). PCNA is directly correlated with the proliferative state of various tissues $[52,54]$.

Green tea extract has a perfect influence on thyroid damage induced by LC. The beneficial impacts of GTE are ascribed to the polyphenolic compounds, particularly the catechins, which constitute $30 \%$ of the dry weight of green tea leaves [16].

With the use of GTE, the level of thyroid hormones increased, while the TSH level decreased. However, the hormonal levels were still away from the control group. BW in the GTE group was comparable to the control group. Weight improvement is mostly explained by increased basal metabolic rates as a consequence of regaining normal thyroid function.

Besides, the expression of PCNA in the GTE group was like the control group. This is mostly attributed to the antiproliferative property of GTE [29].

Apoptosis was considerably improved in the GTE group as the expression of caspase- 3 and $\mathrm{BAX} / \mathrm{Bc} / 2$ ratio was comparable to the control. Moreover, the expression of BAX decreased, while that of $\mathrm{Bc} / 2$ increased. Such protective role of GTE could be explained by its antioxidant effect (decreased MDA/ increased GSH, SOD). The antioxidant effect of GTE was documented in many studies [40, 42]. Catechins and theaflavins of GT are responsible for such antioxidant activity [4].

Besides, we proved the antifibrotic and anti-inflammatory role of GTE as the collagen fibres content and proinflammatory markers (TNF- $\alpha$ and IL-6) decreased compared to the LC group. The anti-inflam- 
matory and antifibrotic roles of GTE were proved in many literature reports $[37,53]$.

There seem to be two major effects of lithium salts in bipolar disorder, i.e. inhibitory action on inositol monophosphatase and inhibition of glycogen synthase kinase-3 activity. No reports in the literature documented any effect of GTE on these enzymes. So, GTE has no harm interfering with lithium action on the brain.

\section{CONCLUSIONS}

In conclusion, prolonged use of LC results in hypothyroidism, which is accompanied by structural thyroid damage. LC induced thyroid damage through oxidative stress that prompted sterile inflammation and apoptosis. With the use of GTE, the thyroid gland regained its structure and function. The protective role of GTE is through its antioxidant, anti-inflammatory, antiproliferative and antifibrotic effects.

\section{Conflict of interest: None declared}

\section{REFERENCES}

1. Adams JM, Cory S. The Bcl-2 protein family: arbiters of cell survival. Science. 1998; 281(5381): 1322-1326, doi: 10.1126/ science.281.5381.1322, indexed in Pubmed: 9735050.

2. Baloch Z, Carayon P, Conte-Devolx B, et al. Laboratory medicine practice guidelines. Laboratory support for the diagnosis and monitoring of thyroid disease. Thyroid. 2003; 13(1): 3-126, doi: 10.1089/105072503321086962, indexed in Pubmed: 12625976.

3. Benhadi N, Fliers E, Visser TJ, et al. Pilot study on the assessment of the setpoint of the hypothalamus-pituitary-thyroid axis in healthy volunteers. Eur J Endocrinol. 2010; 162(2): 323-329, doi: 10.1530/EJE-09-0655, indexed in Pubmed: 19926783.

4. Benzie IFF, Wachtel-Galor S. Herbal Medicine. Biomolecular Clinical Aspects. 2011, doi: 10.1201/b10787.

5. Berens SC, Wolff J, Murphy DL. Lithium concentration by the thyroid. Endocrinology. 1970; 87(5): 1085-1087, doi: 10.1210/endo-87-5-1085, indexed in Pubmed: 4098397.

6. Birben E, Sahiner UM, Sackesen C, et al. Oxidative stress and antioxidant defense. World Allergy Organ J. 2012; 5(1): 9-19, doi: 10.1097/WOX.0b013e3182439613, indexed in Pubmed: 23268465.

7. Bjelakovic G, Nikolova D, Gluud LL, et al. Mortality in randomized trials of antioxidant supplements for primary and secondary prevention: systematic review and meta-analysis. JAMA. 2007; 297(8): 842-857, doi: 10.1001/ jama.297.8.842, indexed in Pubmed: 17327526.

8. D'souza D, Subhas BG, Shetty SR, et al. Estimation of serum malondialdehyde in potentially malignant disorders and post-antioxidant treated patients: A biochemical study. Contemp Clin Dent. 2012; 3(4): 448-451, doi: 10.4103/0976237X.107438, indexed in Pubmed: 23633807.

9. Dhouib $\mathrm{H}$, Jallouli $\mathrm{M}$, Draief $\mathrm{M}$, et al. Oxidative damage and histopathological changes in lung of rat chronically exposed to nicotine alone or associated to ethanol. Pathol Biol (Paris). 2015; 63(6): 258-267, doi: 10.1016/j.patbio.2015.10.001, indexed in Pubmed: 26586280.

10. El-Mahalaway AM, El-Azab NEE. Impacts of resveratrol versus platelet-rich plasma for treatment of experimentally lithium-induced thyroid follicular cell toxicity in rats. A histological and immunohistochemical study. Ultrastruct Pathol. 2019; 43(1): 80-93, doi: 10.1080/01913123.2019.1593270, indexed in Pubmed: 30982377.

11. Focosi $D$, Azzarà A, Kast RE, et al. Lithium and hematology: established and proposed uses. J Leukoc Biol. 2009; 85(1): 20-28, doi: 10.1189/jlb.0608388, indexed in Pubmed: 18809733.

12. Galati G, Lin A, Sultan AM, et al. Cellular and in vivo hepatotoxicity caused by green tea phenolic acids and catechins. Free Radic Biol Med. 2006; 40(4): 570-580, doi: 10.1016/j.freeradbiomed.2005.09.014, indexed in Pubmed: 16458187.

13. George J, Joshi SR. Drugs and thyroid. J Assoc Physicians India. 2007; 55: 215-223.

14. Gordon J, Crutchfield F, Jennings A, et al. Preparation of lipid-free tissue extracts for chromatographic determination of thyroid hormones and metabolites. Arch Biochem Biophys. 1982; 216(2): 407-415, doi: 10.1016/00039861(82)90229-6.

15. Gosselin RE, Smith RP, Hodge HC. Clinical toxicology of commercial products. Williams \& Wilkins, Baltimore 1984.

16. Graham H. Green tea composition, consumption, and polyphenol chemistry. Prev Med. 1992; 21(3): 334-350, doi: 10.1016/0091-7435(92)90041-f.

17. Grossmann M, Weintraub BD, Szkudlinski MW. Novel insights into the molecular mechanisms of human thyrotropin action: structural, physiological, and therapeutic implications for the glycoprotein hormone family. Endocr Rev. 1997; 18(4): 476-501, doi: 10.1210/edrv.18.4.0305, indexed in Pubmed: 9267761.

18. Halliwell B, Gutteridge JM. Free radicals and antioxidant protection: mechanisms and significance in toxicology and disease. Hum Toxicol. 1988; 7(1): 7-13, doi: 10.1177/096032718800700102, indexed in Pubmed: 3278973

19. Hamdy MA, El-Maraghy SA, Kortam MA. Modulatory effects of curcumin and green tea extract against experimentally induced pulmonary fibrosis: a comparison with $\mathrm{N}$-acetyl cysteine. J Biochem Mol Toxicol. 2012; 26(11): 461-468, doi: 10.1002/jbt.21447, indexed in Pubmed: 23132788

20. Hassanin KMA, Abd El-Kawi SH, Hashem KS. The prospective protective effect of selenium nanoparticles against chromium-induced oxidative and cellular damage in rat thyroid. Int J Nanomedicine. 2013; 8: 1713-1720, doi: 10.2147/IJN. S42736, indexed in Pubmed: 23658489.

21. Higdon JV, Frei B. Tea catechins and polyphenols: health effects, metabolism, and antioxidant functions. Crit Rev Food Sci Nutr. 2003; 43(1): 89-143, doi: 10.1080/10408690390826464, indexed in Pubmed: 12587987.

22. Husain K, Somani SM. Interaction of exercise training and chronic ethanol ingestion on testicular antioxidant system in rat. J Appl Toxicol. 1998; 18(6): 421-429, doi: 10.1002/(sici)1099-1263(199811/12)18:6<421::aidjat532>3.0.co;2-r.

23. Kalantari H, Salimi A, Rezaie A, et al. Evaluation of sub-acute oral toxicity of lithium carbonate microemulsion (nano size) on liver and kidney of mice. Jundishapur J Nat Pharm Prod. 2015; 10(1): e22312, doi: 10.17795/jjnpp-22312, indexed in Pubmed: 25866723.

24. Kleiner J, Altshuler L, Hendrick V, et al. Lithium-Induced Subclinical Hypothyroidism. J Clin Psychiatry. 1999; 60(4): 249-255, doi: 10.4088/jep.v60n0409.

25. Kumarguru BN, Natarajan M, Nagarajappa AH. The pathology of lithium induced nephropathy: a case report and review, with emphasis on the demonstration of mast cells. J Clin Diagn Res. 2013; 7(2): 374-377, doi: 10.7860/ JCDR/2013/4448.2774, indexed in Pubmed: 23543788.

26. Kurt A, Tumkaya $L$, Turut $H$, et al. Protective effects of infliximab on lung injury induced by methotrexate. Arch 
Bronconeumol. 2015; 51(11): 551-557, doi: 10.1016/j. arbr.2015.05.012.

27. Lazarus JH. Lithium and thyroid. Best Pract Res Clin Endocrinol Metab. 2009; 23(6): 723-733, doi: 10.1016/j. beem.2009.06.002, indexed in Pubmed: 19942149.

28. Lazarus JH, Bennie EH. Effect of lithium on thyroid function in man. Acta Endocrinol (Copenh). 1972; 70(2): 266-272, doi: 10.1530/acta.0.0700266, indexed in Pubmed: 5068104.

29. Li MJ, Yin YC, Wang J, et al. Green tea compounds in breast cancer prevention and treatment. World J Clin Oncol. 2014; 5(3): 520-528, doi: 10.5306/wjco.v5.i3.520, indexed in Pubmed: 25114865.

30. Ma J, Zou C, Guo L, et al. Novel death defying domain in met entraps the active site of caspase- 3 and blocks apoptosis in hepatocytes. Hepatology. 2014; 59(5): 2010-2021, doi: 10.1002/hep.26769, indexed in Pubmed: 24122846.

31. Mackowiak P, Ginalska E, Nowak-Strojec E, et al. The influence of hypo- and hyperthyreosis on insulin receptors and metabolism. Arch Physiol Biochem. 1999; 107(4): 273-279, doi: 10.1076/1381-3455(199908)107:04;1-q;ft273.

32. McCord JM. Human disease, free radicals, and the oxidant/ antioxidant balance. Clin Bioch. 1993; 26(5): 351-357, doi: 10.1016/0009-9120(93)90111-i.

33. Meister A. Glutathione, ascorbate, and cellular protection. Cancer Res. 1994; 54(7 Suppl): 1969s-1975s, indexed in Pubmed: 8137322.

34. Mezni A, Aoua H, Khazri O, et al. Lithium induced oxidative damage and inflammation in the rat's heart: Protective effect of grape seed and skin extract. Biomed Pharmacother. 2017; 95: 1103-1111, doi: 10.1016/j.biopha.2017.09.027, indexed in Pubmed: 28922729.

35. Misra $H$, Fridovich I. The role of superoxide anion in the autoxidation of epinephrine and a simple assay for superoxide dismutase. J Biol Chem. 1972; 247(10): 3170-3175, doi: 10.1016/s0021-9258(19)45228-9.

36. Nair MP, Mahajan S, Reynolds JL, et al. The flavonoid quercetin inhibits proinflammatory cytokine (tumor necrosis factor alpha) gene expression in normal peripheral blood mononuclear cells via modulation of the NF-kappa beta system. Clin Vaccine Immunol. 2006; 13(3): 319-328, doi: 10.1128/ CVI.13.3.319-328.2006, indexed in Pubmed: 16522772.

37. Ohishi T, Goto S, Monira P, et al. Anti-inflammatory Action of Green Tea. Antiinflamm Antiallergy Agents Med Chem. 2016; 15(2): 74-90, doi: 10.2174/1871523015666160915 154443, indexed in Pubmed: 27634207.

38. Oktay K, Schenken RS, Nelson JF. Proliferating cell nuclear antigen marks the initiation of follicular growth in the rat. Biol Reprod. 1995; 53(2): 295-301, doi: 10.1095/biolreprod53.2.295, indexed in Pubmed: 7492681

39. Ossani GP, Uceda AM, Acosta JM, et al. Role of oxidative stress in lithium-induced nephropathy. Biol Trace Elem Res. 2019; 191 (2): 412-418, doi: 10.1007/s12011-018-1617-2, indexed in Pubmed: 30600502.

40. Peluso I, Serafini M. Antioxidants from black and green tea: from dietary modulation of oxidative stress to pharmacolog- ical mechanisms. Br J Pharmacol. 2017; 174(11): 1195-1208, doi: 10.1111/bph.13649, indexed in Pubmed: 27747873.

41. Ramos-Vara JA, Kiupel M, Baszler T, et al. Suggested guidelines for immunohistochemical techniques in veterinary diagnostic laboratories. J Vet Diagn Invest. 2008; 20(4): 393-413, doi: 10.1177/104063870802000401, indexed in Pubmed: 18599844.

42. Roychoudhury S, Agarwal A, Virk G, et al. Potential role of green tea catechins in the management of oxidative stress-associated infertility. Reprod Biomed Online. 2017; 34(5): 487-498, doi: 10.1016/j.rbmo.2017.02.006, indexed in Pubmed: 28285951.

43. Singer I, Rotenberg D, Puschett JB. Lithium-induced nephrogenic diabetes insipidus: in vivo and in vitro studies. J Clin Invest. 1972; 51(5): 1081-1091, doi: 10.1172/JCI106900, indexed in Pubmed: 4341501.

44. Singhal K, Raj N, Gupta K, et al. Probable benefits of green tea with genetic implications. J Oral Maxillofac Pathol. 2017; 21(1): 107-114, doi: 10.4103/0973-029X.203758, indexed in Pubmed: 28479696.

45. Suvarna SK, Layton C, Bancroft JD. Bancroft's theory and practice of histological techniques. Elsevier, Oxford 2019.

46. Thakur S, Thakur S, Chaube S, et al. Subchronic supplementation of lithium carbonate induces reproductive system toxicity in male rat. Reprod Toxicol. 2003; 17(6): 683-690, doi: 10.1016/s0890-6238(03)00107-2.

47. Thornberry NA, Lazebnik Y. Caspases: enemies within. Science. 1998; 281: 1312-1316.

48. Tipple TE, Rogers LK. Methods for the determination of plasma or tissue glutathione levels. Methods Mol Biol. 2012; 889: 315-324, doi: 10.1007/978-1-61779-867-2_20, indexed in Pubmed: 22669674.

49. Toplan S, Dariyerli N, Ozdemir S, et al. Lithium-induced hypothyroidism: oxidative stress and osmotic fragility status in rats. Biol Trace Elem Res. 2013; 152(3): 373-378, doi: 10.1007/s12011-013-9629-4, indexed in Pubmed: 23408263.

50. Tsujimoto $\mathrm{Y}$. Role of $\mathrm{Bcl}-2$ family proteins in apoptosis: apoptosomes or mitochondria? Genes Cells. 1998; 3(11): 697-707, doi: 10.1046/j.1365-2443.1998.00223.x, indexed in Pubmed: 9990505.

51. Valle FC, Hayashi H, Prates JC, et al. Cellular and subcellular alterations of the thyroid gland in rats caused by lithium carbonate. Bull Assoc Anat (Nancy). 1993; 77: 39-43.

52. Velický J, Titlbach M, Lojda Z, et al. Expression of the proliferating cell nuclear antigen (PCNA) in the rat thyroid gland after exposure to bromide. Acta Histochem. 1997; 99(4): 391-399, doi: 10.1016/s0065-1281(97)80032-3.

53. Wang L, Yang G, Yuan Li, et al. Green tea catechins effectively altered hepatic fibrogenesis in rats by inhibiting ERK and Smad1/2 phosphorylation. J Agric Food Chem. 2019; 67(19): 5437-5445, doi: 10.1021/acs.jafc.8b05179, indexed in Pubmed: 30424599.

54. Zhong W, Peng J, He H, et al. Ki-67 and PCNA expression in prostate cancer and benign prostatic hyperplasia. Clin Invest Med. 2008; 31(1): E8-EE15, doi: 10.25011/cim.v31i1.3136, indexed in Pubmed: 18312749 